\title{
Small Amine Molecules: Solvent Design Toward Facile Improvement of Protein Stability Against Aggregation and Inactivation
}

\author{
Kentaro Shiraki ${ }^{1, *}$, Shunsuke Tomita ${ }^{2}$ and Naoto Inoue ${ }^{1}$ \\ ${ }^{1}$ Faculty of Pure and Applied Sciences, University of Tsukuba, 1-1-1 Tennodai, Tsukuba, Ibaraki 305- \\ 8573, Japan; ${ }^{2}$ Biomedical Research Institute, National Institute of Advanced Industrial Science and \\ Technology, 1-1-1 Higashi, Tsukuba, Ibaraki 305-8566, Japan
}

\begin{abstract}
Proteins are prone to inactivation in aqueous solutions because chemical modification and aggregation usually occur, particularly at high temperature. This review focuses on the recent advance in practical application with amine compounds that prevent the heat-induced inactivation and aggregation of proteins. Coexistence of amine solutes, typically diamines, polyamines, amino acid esters, and amidated amino acids decreases the heat-induced inactivation rate of proteins by one order of magni-

Kentaro Shiraki tude compared with that in the absence of additives under low concentrations of proteins at physiological $\mathrm{pH}$. The amine compounds mainly suppress chemical modification, typically the $\beta$-elimination of disulfide bond and deamidation of asparagine side chain, thereby preventing heat-induced inactivation of proteins. Polyamines do not improve the refolding yield of proteins, owing to decrease in the solubility of unfolded proteins. In contrast, arginine is the most versatile additive for various situations, such as refolding of recombinant proteins, solubilized water-insoluble compounds, and prevention of nonspecific binding to solid surfaces; however, it is not always effective for preventing heat-induced aggregation. Amine compounds will be a key to prevent protein inactivation in solution additives.
\end{abstract}

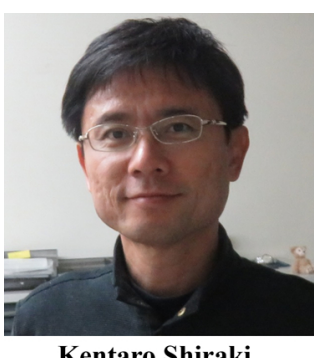

Keywords: Amine compound, arginine, polyamine, amino acid derivative, protein aggregation, protein inactivation, solvent additive.

\section{INTRODUCTION}

Proteins are unstable in aqueous solution. The instability of proteins poses a serious problem for their application in purification, shipping, storage, and handling. The causes of protein inactivation can be classified into physical and chemical processes; the former involves structural unfolding and aggregation, whereas the latter involves chemical modification [1]. Various kinds of low molecular weight additives have been developed to avoid protein inactivation and aggregation [2].

This review focuses on the amine compounds that prevent the heat-induced inactivation and aggregation of proteins as solvent additives and provides the following information: 1) We summarize a systematic property of amine compounds that prevents the heat-induced inactivation and aggregation of proteins, such as amino acids, amino acid alkylesters, amidated amino acids, diamines, and naturally occurring polyamines; 2) We introduce the major causes for chemical modifications of proteins, deamidation of Asn residue, $\beta$-elimination of disulfide bond, and disulfide exchange; 3) We describe the prevention of such chemical modification by amine compounds from heat treatment. The inhibition of chemical modifications results in the prevention of heatinduced inactivation of proteins; 4) We introduce the most

*Address correspondence to this author at the Faculty of Pure and Applied Sciences, University of Tsukuba, 1-1-1 Tennodai, Tsukuba, Ibaraki 3058573, Japan; Tel/Fax: +81-29-853-5306; E-mail: shiraki@bk.tsukuba.ac.jp well-known additive Arg. Arginine prevents the heat-induced aggregation of proteins as well as increases the solubility of aromatic compounds and aggregation-prone unfolded proteins; 5) We discuss the additives regarding the distinction between heat-induced aggregation and refolding-induced misfolding. Finally, we discuss why amine compounds from living cells prevent the heat-induced degradation of proteins.

\subsection{Amine Compound Prevents Heat-induced Inactiva- tion and Aggregation of Proteins}

Several studies have reported on amine compounds as solvent additives for the prevention of heat-induced inactivation and aggregation under similar conditions, namely heat treatment at $98^{\circ} \mathrm{C}$ at neutral $\mathrm{pH}(\mathrm{pH} 6.5-7.5)$ and relatively low protein concentration $(0.2-1.0 \mathrm{mg} / \mathrm{ml})$ for model proteins such as hen egg white lysozyme and bovine ribonuclease A (RNase A). The chemical structures of the reported amine additives and related compounds are shown in (Fig. 1). It should be noted that additives that prevent heat-induced inactivation and aggregation have amine groups. Firstly, we briefly summarize the existing data of heat-induced inactivation and aggregation with additives as follows:

i) Arg achieves a stronger effect in preventing the heatinduced aggregation of proteins than the other naturallyoccurring amino acids for lysozyme and other model proteins such as Candida rugosa lipase, bovine trypsin, bovine $\alpha$-chymotrypsinogen, bovine RNase A, horse myoglobin, 
bovine cytochrome c, and concanavalin A [3]. The additives were used at $0.2 \mathrm{M}$ and $0.5 \mathrm{M}$. Arg has commonly been used as a protein refolding additive since a quarter of a century [4]; however, Shiraki et al. pointed out a new application of Arg as additive that prevents the heat-induced aggregation of proteins [3].
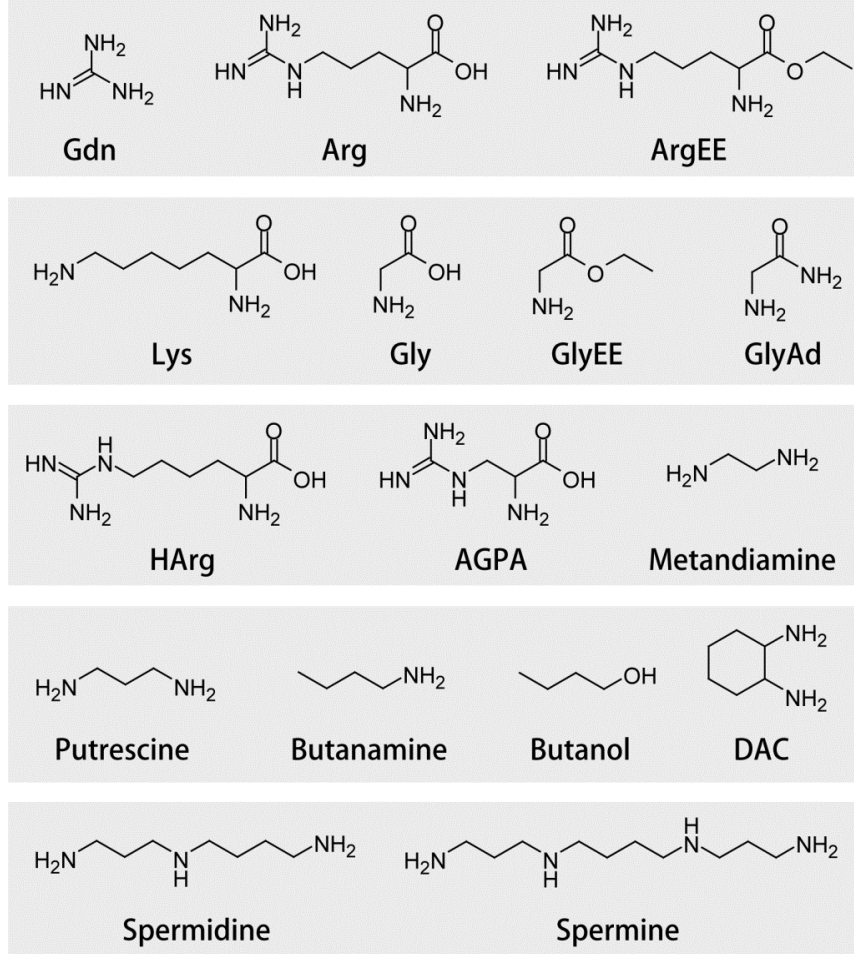

Fig. (1). List for the chemical structures of additives. Gdn (guanidine hydrochloride), Arg (arginine), ArgEE (arginine ethylester), Lys (lysine), Gly (glycine), GlyEE (glycine ethylester), GlyAd (glycine amide), HArg (homo-arginine), AGPA (2-amino-3propionic acid), and DAC (1,2-diaminocyclohexane).

ii) Arg ethylester (ArgEE) was more effective in preventing both the heat-induced inactivation and aggregation of lysozyme than Arg [5]. Heat-induced inactivation and aggregation of $1.0 \mathrm{mg} / \mathrm{ml}$ lysozyme at $\mathrm{pH} 7.1$ was apparently a single-exponential process even in the absence and presence of additives; the rate constants of heat-induced inactivation were $7.0 \times 10^{-3} \mathrm{~s}^{-1}$ (no additive), $4.2 \times 10^{-3} \mathrm{~s}^{-1}$ (in $0.1 \mathrm{M}$ Arg), and $1.2 \times 10^{-3} \mathrm{~s}^{-1}$ (in $0.1 \mathrm{M} \mathrm{ArgEE}$ ). The inactivation results from both irreversible unfolding of the tertiary structure and chemical modification on the catalytic site, though the cited study shows the difference in the inactivation rate without further discussion.

iii) It was serendipitously found that all varieties of amino acid alkylesters, as well as ArgEE, prevented both heat-induced inactivation and aggregation of lysozyme more effectively than amino acids themselves [6]. Glycine ethylester (GlyEE) was more effective in the heat-induced inactivation and aggregation of lysozyme than ethylene glycol monoester, guanidine, and Gly. Similarly, amidated amino acids, including glycineamide (GlyAd), prevented the heat- induced inactivation and aggregation of lysozyme [7]. These data indicate that the modification of the carboxyl group of the amino acids is favorable for the heat-induced degradation of proteins.

iv) Arg derivatives (homo-arginine, Arg amide, and 2-amino-3-guanidinopropionic acid) increased the refolding yield of lysozyme from a reduced and denatured state compared to Arg [8]. A comparative analysis of amino acid derivatives as co-solutes revealed that amino acid alkylesters and amidated amino acids act as favorable additives for preventing the heat-induced degradation of proteins [9], while Arg derivatives are favorable for increasing the refolding yield of lysozyme. It is interesting that heat-induced inactivation is a different mechanism from the refolding-induced misfolding. This viewpoint will be discussed later.

v) Linear aliphatic diamines (1,3-diaminopropane, 1,4diaminobutane, and 1,5-diaminopentane) at $0.1 \mathrm{M}$ prevented the heat-induced inactivation and aggregation of $0.2 \mathrm{mg} / \mathrm{ml}$ lysozyme [10]. Note that the diols (i.e., 1,3-propanediol, 1,4butanediol, and 1,5-pentanediol) did not prevent the heatinduced inactivation and aggregation of lysozyme. Arrhenius plots showed linear correlation between the temperature of the heat treatment and residual activity after the heat treatment in the presence or absence of diamines [10], meaning that a dominant single rate-limiting step controls the early stage of the heat-induced inactivation of lysozyme, which is possibly a chemical modification.

vi) Other amine compounds, such as the naturallyoccurring polyamines of putrescine, spermidine, and spermine [11], and the synthetic compounds of 1,2diaminocyclohexane, 1,3-diaminocyclohexane, and 1,4diaminocyclohexane [12] were found to be superior suppressors of the heat-induced inactivation and aggregation of lysozyme and RNase A. The rate constants of heat-induced inactivation and aggregation at $98^{\circ} \mathrm{C}$ of lysozyme were one order of magnitude higher than those in the presence of 0.1 $\mathrm{M}$ diamines. The $\mathrm{pH}$-dependent experiment showed that the charged state of diamines plays an important role for the prevention of thermal degradation [12].

vii) Inorganic ammonium salts prevented heat-induced aggregation more effectively than sodium salts [13]. For example, $0.6 \mathrm{M} \mathrm{NH}_{4} \mathrm{Cl}$ and $\left(\mathrm{NH}_{4}\right)_{2} \mathrm{SO}_{4}$ as co-solutes decreased the aggregation rate of lysozyme by one-order magnitude compared with $\mathrm{NaCl}$ and $\mathrm{Na}_{2} \mathrm{SO}_{4}$. Aggregation rates of lysozyme in various salts were in good correlation with the molar surface tension increment of solvents, except for ammonium salts; thus, it was concluded that ammonium salts possess a function that prevents the thermal aggregation of proteins, rather than surface tension with the Hofmeister effect.

The above-mentioned data indicate that amine compounds, including ammonium ions, prevent the heat-induced inactivation and aggregation of proteins. As described below, the molecular mechanisms of the amine compounds acting as additive are mainly triggered by the prevention of chemical modifications, which would lead to the prevention of the irreversible inactivation of proteins. 


\subsection{Chemical Modifications of Protein by Heat Treat- ment}

Chemical modifications of protein by heat treatment have been well documented during the 1980s. Dr. Klivanov et al. examined the chemical modifications of hen egg white lysozyme and bovine RNase A as models when treated at high temperature [14-17]. As shown in (Fig. 2), the chemical modifications of proteins were classified into five kinds: 1) deamidation of Asn and Gln side chains; 2) $\beta$-elimination of disulfide bond; 3) disulfide bond exchange of Cys; 4) oxidation of Met and Cys side chains; and 5) hydrolysis of the peptide bond with Asp.

Deamidation of the side chains of Asn and Gln (Fig. 2A) frequently occurs among chemical modifications at broad $\mathrm{pH}$ ranges $[18,19]$, which is one of the main problems hampering the production of pharmaceutical antibody byproducts [20] and sample preparation for mass spectroscopy [21]. The molecular mechanism of deamidation was well investigated using a hexapeptide as a model [22]. Under the neutral or weak alkaline $\mathrm{pH}$ (typically $\mathrm{pH}$ 7-11), peptide deamidation occurs via a cyclic imide intermediate, while under the acidic $\mathrm{pH}$, the Asn side chain directly undergoes hydrolysis. The deamidation rate of Asn is one order of magnitude faster than that of Gln.

Disulfide bond-linked Cys side chains stabilize the thermodynamic structure of the native state by decreasing the conformation entropy of the unfolded state. However, the disulfide bond is prone to cause $\beta$-elimination (Fig. 2B) from neutral to alkaline $\mathrm{pH}$ ranges [16], such as monoclonal antibody during storage [23] and sample preparation for mass spectroscopy [24]. The occurrence of $\beta$-elimination triggered the deprotonation of $\mathrm{C} \alpha-\mathrm{H}$ bonds by base catalyst, followed by the formation of thiocysteine and dehydroalanine [25]. Thiocysteine further degrades other sulfur compounds. Subsequently, the product dehydroalanine is prone to link with the Lys side chain.

The thiolate ion on Cys side-chain is an active nucleophile; thus, the sulfur atom of the dislfide bond is subjected to nucleophilic attack by thiolate ion. The disulfide bond exchange also occurs under a high concentration of protein at weak alkaline pHs $[26,27]$. Such disulfide bond exchange causes protein aggregation by intermolecular cross-linking under high concentrations of proteins $(>1 \mathrm{mg} / \mathrm{ml})$ around weak alkaline $\mathrm{pH}$ (around approximately the isoelectric point of the thiol side chain, $\mathrm{pH} 8.2$ ).

Other chemical reactions are also known; the oxidation of sulfur containing amino acids (Met and Cys) (Fig. 2C) and hydrolysis of peptide bond occur during heat treatment in aqueous solutions. Met and Cys in polypeptide are oxidized in aqueous solution $[28,29]$. The $\mathrm{C}$-terminus of Asp residue is prone to hydrolyze under weak-acidic condition [30].

The main causes of chemical modification at approximately neutral $\mathrm{pHs}$ at high temperature are deamidation, $\beta$-elimination, and disulfide exchange. As described below, $\beta$-elimination and deamidation are dominant causes at low protein concentration (typically $<1.0 \mathrm{mg} / \mathrm{ml}$ ), while disulfide bond exchange is the dominant cause with increasing concentrations of proteins. The practical application of amine compounds as additives that prevents such chemical modifications is described below.

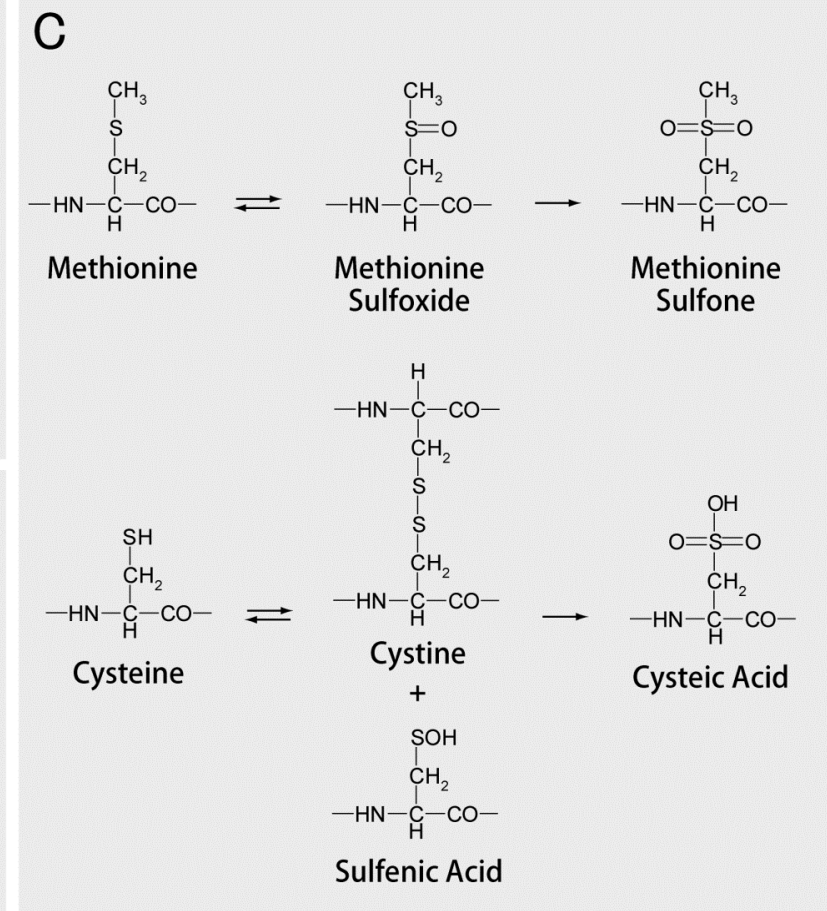

Fig. (2). Main chemical modifications of proteins in aqueous solution. (A) Deamidation of the Asn side chain via a cyclic imide intermediate. (B) $\beta$-elimination of the disulfide bond. (C) Oxidation of Met and Cys side chains. 


\subsection{Amine Compounds Prevent $\beta$-elimination of the Disulfide Bond and Deamidation of the Asn Side Chain}

To investigate amine co-solutes in general, inactivation rates were compared with lysozyme and RNase A in the presence of eight kinds of additives, namely Arg, Gly, Lys, guanidine (Gdn), GlyAd, spermidine, $\mathrm{NaCl}$, and $\mathrm{NH}_{4} \mathrm{Cl}$ [31]. The half-life time of the enzyme activity $\left(\tau_{1}\right)$ treated at $98^{\circ} \mathrm{C}$ was $3.6 \mathrm{~min}$ under the condition at $1.0 \mathrm{mg} / \mathrm{ml} \mathrm{RNase} \mathrm{A}$ in 50 $\mathrm{mM} \mathrm{Na-phosphate} \mathrm{buffer} \mathrm{(pH} \mathrm{7.0;} \mathrm{Fig.} \mathrm{3A).} \mathrm{In} \mathrm{the} \mathrm{presence}$ of additives, the $\tau_{1}$ values varied from $4.5 \mathrm{~min}(\mathrm{NaCl})$ to 41.1 min (GlyAd). As expected, the order is similar to that previously reported; amine compounds decreased the inactivation rate of the enzyme. GlyAd was the most favorable additive to prevent the heat-induced inactivation of both enzymes; the order of the effects of additives was GlyAd $>$ spermidine $>$ $\mathrm{NH}_{4} \mathrm{Cl}>\mathrm{Arg}=\mathrm{Lys}>\mathrm{Gly}=\mathrm{Gdn}=\mathrm{NaCl}$. A similar order was obtained for the inactivation rate of lysozyme from 2.6 $\min (\mathrm{Gdn})$ to $19.5 \mathrm{~min}$ (GlyAd).
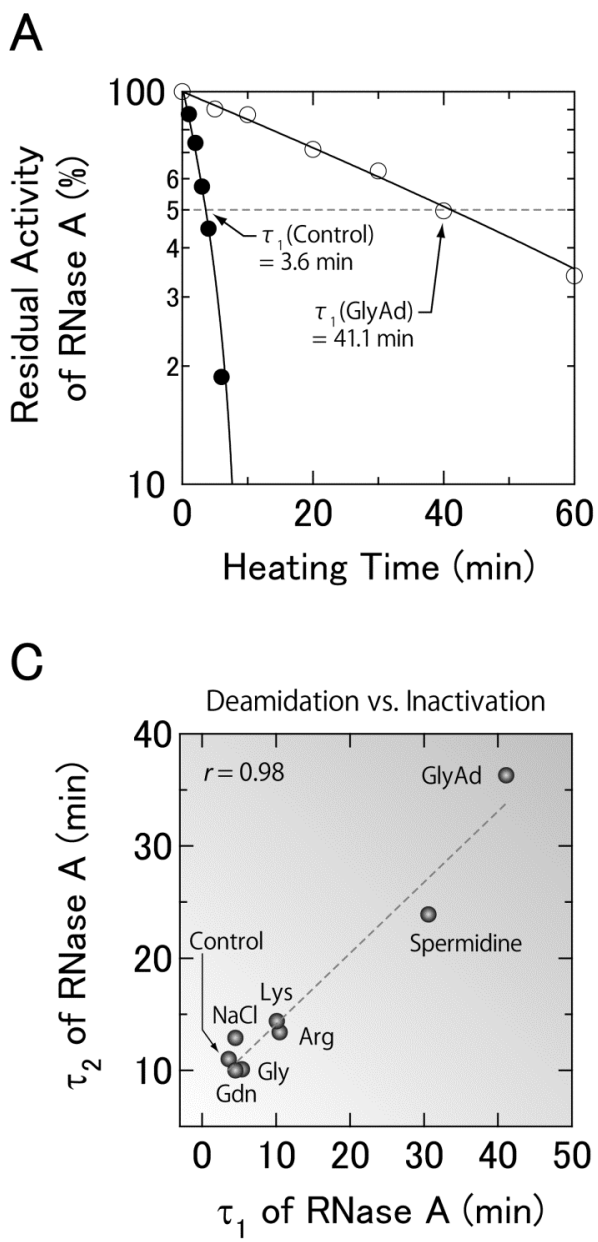

From the results, it was concluded that the suppressive effects of additives for heat-induced inactivation are because of their abilities to suppress the intrinsic chemical modifications of proteins. The most important point is the clear correlation between the inactivation rate of RNase $\mathrm{A}$ and lysozyme with the correlation coefficient of 0.98 in the presence of eight kinds of additives (Fig. 3B). Moreover, the deamidation rate of the Asn side chain of RNase A and lysozyme decreased in the order GlyAd $>$ spermidine $>$ Lys $>$ Arg, which is correlated to the inactivation rate of both proteins in the presence of these additives (Fig. 3C). Similarly, the $\beta$-elimination of the proteins decreased in the almost same order (Fig. 3D). Thus, these results indicate that amine compounds prevent the chemical modifications such as deamidation and $\beta$-elimination, leading to the prevention of thermal degradation of proteins.

In addition, the question of why amine co-solutes prevent such chemical modifications of proteins is interesting. Amine compounds are also cations; for example, polyamines
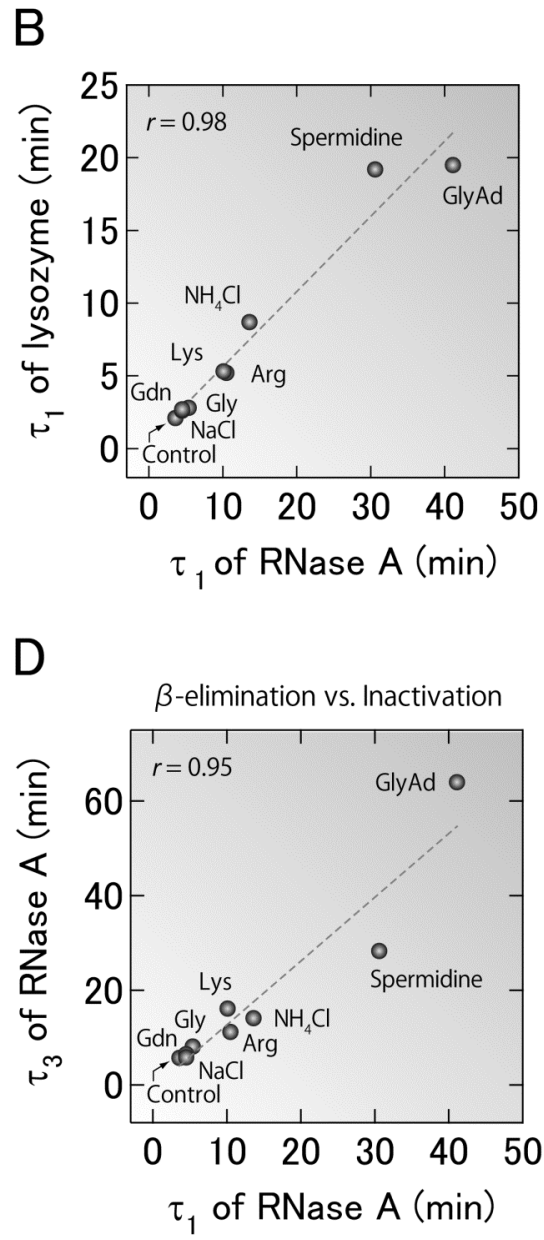

Fig. (3). Thermal inactivation of RNase A and lysozyme in the presence of additives. The protein of $1.0 \mathrm{mg} / \mathrm{ml} \mathrm{with} 200 \mathrm{mM}$ additives and $50 \mathrm{mM}$ Na-phosphate ( $\mathrm{pH} 7.0$ ) were heated at $98^{\circ} \mathrm{C}$, and then the residual activity, deamidation, and $\beta$-elimination were determined. (A) The residual activity of RNase $A$ after the heat treatment at respective time. The value of $\tau_{1}$ is defined as the half-life time of the residual activity of enzyme. (B) The correlation between $\tau_{1}$ of RNase A and $\tau_{1}$ of lysozyme after the heat treatment in the presence of additives. (C) The correlation between $\tau_{1}$ and the time for deamidation of one Asn residue per a protein $\left(\tau_{2}\right)$ of RNase A after the heat treatment in the presence of additives. (D) The correlation between $\tau_{1}$ and the time for $\beta$-elimination of 0.2 disulfide bond per a protein $\left(\tau_{3}\right)$ of RNase A after the heat treatment in the presence of additives. The $r$ values in figures are correlation coefficients. The raw data were obtained from a previous study [31]. 
interact with the negatively charged region on proteins as a polycation that may protect the chemical modification. However, the binding between proteins and small amine compounds is too weak to identify the binding assay by surface plasmon resonance (SPR) and the structural biology by x-ray crystallography and nuclear magnetic resonance (NMR). Molecular dynamics simulation suggests weak binding between the enzyme chymotrypsin and polyamines [32]. Thus, in the future, the precise chemical mechanism may be described by quantum mechanics by calculation combined with various spectroscopic techniques.

From an industrial and experimental application point of view, $50-100 \mathrm{mM}$ GlyAd or polyamine is recommended as an additive in protein solution when the prevention of chemical degradation and protein inactivation during storage and shipping at high temperature is preferred. $\mathrm{NH}_{4} \mathrm{Cl}$ will be required at high concentration, such as $500 \mathrm{mM}$. In addition, Arg at $100-500 \mathrm{mM}$ is a good condition for a solution when noncovalent interactions between proteins and/or proteins and solid surfaces are the driving force for the inactivation and aggregation of the proteins, as described below.

\subsection{Arginine is a Versatile Additive that Prevents Physi- cal Aggregation Rather than Chemical Inactivation}

Arg is currently a well-known additive within biotechnology and pharmaceutics, as demonstrated in a comprehensive review by Dr. Arakawa and co-worker [33]. Arg as an additive appeared for the first time in the application of the refolding method on recombinant proteins. During the 1980s, Dr. Rudolph discovered Arg as a refolding additive on the recombinant full-length tissue-type plasminogen activator, as described in a well-documented review article for refolding of recombinant proteins [34], fab-fragment refolding [35], and suppression of aggregation [36]. The pioneering work using Arg as an additive outlined the refolding of a recombinant Fab-fragment from the inclusion body to the native state [4]. After the discovery, Arg has been use for the refolding of many medical proteins, including immunotoxin from monoclonal antibody fused with Pseudomonas exotoxin A [37], truncated tissue-type plasminogen activator [38], rabbit heterotetrameric casein kinase II [39], interleukin-6 receptor [40], Psedomonas fluorescens lipase [41], human neurotrophin-3 [42], human and mouse single-chain Fv fragments [43], human interleukin-21 [44], and human interleukin-10 [45]. Furthermore, Arg-assisted refolding technology has been practically enhanced for "step-wise dilution" [46], the synergistic effect of Arg with kosmotropic ions [47] or a weak detergent of lauroyl-L-glutamate and Arg [48] and on the column refolding of a monomeric noncollagenous domain of Type IV collagen [49].

It has been pointed for over two decades that the guanidino group of Arg stacks parallel with aromatic side chains [50], although the aromatic group is prone to being bound to the amino group [51] and cation [52]. Moreover, Arg increases peptide and protein solubility, such as an aromaticrich insulin segment of FFYTP [53], gluten [54], reduced carboxymethyl lysozyme [9], and porcine myosin [55], several times higher than those in the absence of any additives. Thermodynamic analyses revealed that Arg does not decrease the melting temperature of lysozyme as a model pro- tein $[3,5]$. Arg is not a protein denaturant; however, it perturbs local structure around the aromatic amino acid of proteins $[56,57]$. Moreover, x-ray crystallographic analyzes of hen egg lysozyme showed that three Arg molecules as additives are observed on an aromatic surface [58] and hydration water molecules are increased with increasing concentration of Arg molecules [59].

A quantitative experiment showed the transfer free energies from water to $1.0 \mathrm{M} \mathrm{Arg} \mathrm{solution} \mathrm{of} \mathrm{small} \mathrm{aromatic}$ compounds; coumarin was $2 \mathrm{~kJ} / \mathrm{mol}$ [60]; the nucleobases adenine, guanine, cytosine, thymine, and uracil were 1-2 $\mathrm{kJ} / \mathrm{mol}$ [61-63]; alkyl gallates were $3 \mathrm{~kJ} / \mathrm{mol}$ [64]; caffeic acid was $5 \mathrm{~kJ} / \mathrm{mol}$ [65]. These data showed that Arg increases the solubility of aromatic compounds, resulting from cation- $\pi$ noncovalent interaction. The molecular mechanism of Arg as an additive is briefly summarized as follows:

i) Prevention of chemical modification. In addition, Arg prevents the heat-induced chemical modifications of proteins, as described in the current review. However, the preventive effect of Arg on chemical modification is not extraordinary but normal, as shown in (Fig. 3).

ii) Gap effect. The chemically inactive molecule of neutral crowder increased the activation energy for association between proteins, leading to a decrease in the binding energy. The "gap theory" is favorably described by the Arg function on macromolecules [66, 67], $\alpha$-chymotrypsinogen A, and melittin [68]. Various sizes of self-associated Arg molecules may function as crowders to prevent protein aggregation [69].

iii) Specific interaction. Cation- $\pi$ interaction of the amino acid residues is commonly observed in a protein tertiary structure and protein interface [70, 71]. Similarly, Arg molecules bind to proteins [58] and small compounds [61] with cation- $\pi$ interaction. In addition, electrostatic interaction and hydrogen bonds occur. A cationic guanidium group can bind to an anion. Moreover, the binding free energy of the ionpair between guanidium and phosphate are $-4.1 \mathrm{~kJ} / \mathrm{mol}$ from theoretical computational calculation [72] and $-2.4 \mathrm{~kJ} / \mathrm{mol}$ from experimental work [73]. Such enthalpic binding may promote aggregation, while guanidine-aromatic interaction solubilizes proteins [74].

iv) Solvent effect. It is to be noted that amino acids are preferentially excluded from protein surfaces [75], leading to the stabilization of the folded and compact state of proteins $[76,77]$. Arg also increases the surface tension of water [78]; hence, Arg is basically excluded from protein surfaces. Thus, it may be concluded that Arg molecules bind to the protein surface with very low energy derived from cation- $\pi$ and other specific interactions. In other words, this marginal effect of Arg additive on protein structures results in an outstanding versatility for troublesome protein solutions in any situations.

v) Salt effect. Arg often uses at neutral pHs in buffer solution. Arg solution is prepared by dissolution of the powder of arginine monohydrochloride $(\mathrm{ArgHCl})$ or Arg base into buffer solution, followed by $\mathrm{pH}$ is adjusted with $\mathrm{NaOH}$ or $\mathrm{HCl}$ toward the desired neutral $\mathrm{pH}$. Accordingly, the Arg solution is a kind of salts solution. Actually, Arg and Lys decrease the viscosity of high concentration of bovine (275 
$\mathrm{mg} / \mathrm{ml})$ and human $(305 \mathrm{mg} / \mathrm{ml})$ serum albumin solutions as similar extent to the $\mathrm{NaCl}$ and guanidine hydrochloride solutions [79]. The decrease in viscosity results from the salt effect that decreases the repulsion between high concentration albumins. It is noted that $\mathrm{ArgHCl}$ specifically decreases the viscosities of high concentration of gamma globulins from human and bovine among amino acids and salts, including lysine hydrochloride and $\mathrm{NaCl}$ [80]. Taken together, Arg solution decreases the protein viscosity both salt effect and Arg-specific interaction effects.

These complex mechanisms of Arg with chemical reaction, specific interaction, and bulk effect result in the controversial appearance as a solvent additive that prevents the thermal aggregation of proteins [33]. For example, Arg did not prevent the heat-induced aggregation of human growth hormones and interferon- $\alpha 2 b$ [81] because Arg at low concentration $(<0.1 \mathrm{M})$ promotes aggregation by the suppression of electrostatic repulsion as salt effect. Similarly, Arg promotes heat-induced aggregation for the large immunoglobulin G1 protein [82] and the $\beta$-lactoglobulin ( $\beta L G)$ oligomeric protein [74]. Such structurally unstable proteins can be stabilized by the use of Arg with the acidic amino acids Glu and Asp [82] and the kosmotropic ions [47]. Thus, it is possible that Arg promotes the heat-induced aggregation of large and complex proteins at low concentration. It is noted that Arg does not prevent amyloid-like fibril aggregation of hen egg lysozyme induced by heat treatment at acidic $\mathrm{pH}$ [83]. The difference between thermal aggregation and amyloid fibrillization will be a key to understand the molecular mechanism of Arg on protein aggregation.

\subsection{Difference between Heat-induced Degradation and Refolding-induced Misfolding}

A deeper examination of the molecular mechanism of additives could facilitate a discussion of the difference between refolding-induced misfolding and heat-induced degradation. Figure $\mathbf{4}$ shows a simple scheme of protein refolding. Recombinant proteins usually form inclusion bodies (insoluble and inactive aggregates) when expressed in host cells. Thus, the refolding is an indispensable process necessary to recover the native-state protein from the inclusion body. Firstly, the inclusion body should be solubilized using a reducing reagent (ex. dithiothreitol, 2-mercaptoethanol, or glutathione) with a high concentration of a denaturant (ex. $\mathrm{GdnHCl}$ or urea). Then, the reduced and unfolded state protein $\left(U_{R}\right)$ is diluted into a large amount of buffer. During this step, some proteins refold spontaneously into its native structure according to Anfinsen's thermodynamic dogma (process (2) in Fig. 4), while the others form amorphous aggregates (process (3) in Fig. 4).

To increase the refolding yield of proteins, various techniques have been developed. The early stage of the refolding methods has been well documented by Dr. Rudolph [34, 35] and Dr. Clark $[84,85]$. The fundamental approach to increasing the refolding yield of proteins is to decrease the irreversible aggregation. For example, the denaturant of urea is gradually removed by controlled dialysis [86]; detergent solubilizes the aggregation-prone folding intermediate, and then the detergent is stripped off the protein surface, so called "artificial chaperones" [87]; nano-scale pore isolates the aggregation-prone folding intermediate, followed by the controlled release by polyethylene glycol, which leads to a decrease in the probability of aggregation [88]. During the dilution step of the denaturant, the addition of 0.2-1.0 M Arg can prevent protein aggregation [89]. Arg is substituted for diluted denaturant that prevents intermolecular interaction between aggregation-prone folding and the intermediate state of proteins.

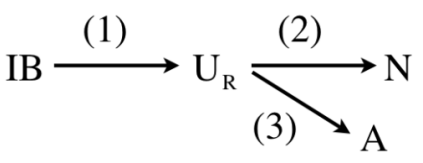

Fig. (4). Refolding process from the inclusion body (IB) of a recombinant protein. (1) The recombinant protein of the inclusion body is solubilized by the reducing reagent and a high concentration of denaturant. Following this, (2) the reduced and unfolded protein $\left(U_{R}\right)$ is refolded to the native state $(N)$ by various refolding methods. However, (3) the refolding process competes with aggregation (A). The refolding process of (2) is basically spontaneous folding; thus, refolding methods are designed to suppress the side reaction of (3).

By contrast, heat-induced inactivation is shown in (Fig. 5). Amine compounds prevent chemical degradation during heat treatment (Process (2) in Fig. 5). After the heat treatment, an unfolded molecule refolds spontaneously into the native state and the other unfolded molecule forms an aggregate. Moreover, the heat-induced aggregates of lysozyme possess higher $\beta$-sheet content than those of refoldinginduced aggregates, as quantified by Fourier-transform infrared (FT-IR) spectroscopy [90]. It is noted that intermolecular disulfide bond exchanges occurred during heat treatment; however, this is not a crucial step when protein concentration is $\leq 1 \mathrm{mg} / \mathrm{ml}$.

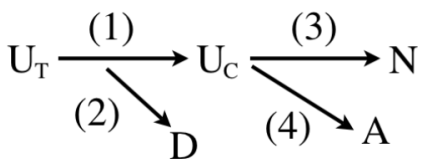

Fig. (5). Heat-induced inactivation and aggregation of protein. First, protein is thermally unfolded at high temperature $\left(U_{T}\right)$. During the heat treatment of (1), the unfolded molecule gradually degrades chemically and structurally (D) during process (2). Subsequently, the samples are cooled down to room temperature $\left(\mathrm{U}_{\mathrm{C}}\right)$. The $U_{C}$ molecules are immediately refolded into the native state $(\mathrm{N})$ or an irreversible aggregate (A). The solution additive affects the suppression of the processes (2) and (4). It is thought that amine compounds prevent chemical inactivation in the process of (2), while Arg mainly prevents the aggregation process of (4).

The difference between amine compounds (typically spermidine), Arg, and guanidine has been systematically investigated for refolding yield and for the heat-induced inactivation of lysozyme as a model [90]. The following results obtained were clear: 1) Guanidine and Arg increase the solubility of reduced and carboxymethylated (RCM)- 
lysozyme, while spermidine does not; 2) spermidine suppresses the heat-induced inactivation and aggregation of lysozyme; and 3) guanidine and Arg increase the refolding yield of lysozyme. These data support the following hypothesis: guanidine and Arg primarily increase the solubility of an aggregation-prone molecule, leading to the prevention of the irreversible inactivation of proteins (process (4) in Fig. 5). On the other hand, spermidine primarily suppresses the chemical modifications of proteins caused by heat treatment (process (2) in Fig. 5), leading to the suppression of the heatinduced inactivation of proteins.

Furthermore, five kinds of amino acids (Arg, Lys, Glu, Ser, and citrulline) and their derivatives have been investigated for clarifying the indispensable chemical structure of additives for refolding and heat treatment [9]. The additives that prevent refolding-induced aggregation possess guanidium or ureido groups (Fig. 6). Guanidine and urea are known as protein denaturants. These kinds of chemicals are bound to the hydrophobic surface that solubilizes aggregation-prone molecules, which indirectly increases the refolding yield of proteins as the aggregation suppressor. On the other hand, the additives that prevent heat-induced inactivation possess a principal amino acid chain (Fig. 6). This is because the heatinduced inactivation mainly results from the chemical modifications of proteins. It is interesting to note that the suppressive effect of Arg on heat-induced aggregation of $\alpha$ chymotrypsin retains constant when temperature different from $65^{\circ} \mathrm{C}$ to $85^{\circ} \mathrm{C}$, while that of a small poly(ethylene glycol) of tetraethylene glycol (TEG) increases with increasing temperature [91]. This results from the increase in hydrophobic interaction between TEG and unfolded protein with increasing temperature.

\section{CELLULAR AMINES}

Finally, we would like to mention amine compounds in living cells. Spermine, spermidine, and putrescine are universally distributed in all living materials [92]. Cellular poly- amines electrostatically bind to negatively charged macromolecules, typically DNA and RNA; hence, they stabilize (or destabilize) their tertiary structure. The nonspecific binding to the negative region of polyamines on macromolecules are involved in many cellular functions, such as cell growth, survival, proliferation, metabolism regulation, drag response, and diseases [93,94]. These compounds in vivo may prevent the chemical degradation of proteins [11] as well as the degradation of DNA and RNA. Their function to prevent the chemical degradation of macromolecules serves to remind us that organic solute "osmolyte" in living cells exists in an extreme environment [95]. The osmolytes reduce the structural and functional damages of macromolecules under stressful condition, such as trimethylamine-N-oxide, taurine, $\beta$-alanine, polyols, and sugars. It should be pointed out that these chemicals are amine compounds. The osmolytes play an important role in the extreme environment that resists osmotic water stress on macromolecules. Furthermore, these osmolytes may facilitate the prevention of chemical damage in living cells.

Hyperthermophiles exist in an environment at a temperature $>85^{\circ} \mathrm{C}$; hence, hyperthermophilic proteins should have high conformational stability under high temperature as compared with that of their mesophilic counterpart proteins [96-98]. In general, high temperature accelerates the chemical reaction [99]. Thus, it is known that the amino acid composition of a hyperthermophilic protein is different from that of its mesophilic counterpart; moreover, Asn, Gln, Cys, and Met in hyperthermophilic proteins occur at lower contents than in mesophilic proteins $[100,101]$. Although the tertiaryfolded state of protein is characterized by a higher tolerance of deamidation than the disulfide-reduced and proteasedigested state peptide [99], these heat-labile amino acids are also degraded by such high temperature environment. It is noted that hyperthermophiles have unique polyamines in the cells [102-105]. Thus, polyamines may prevent the thermal degradation of thermophilic proteins under extreme conditions.

\section{Refolding Heating}

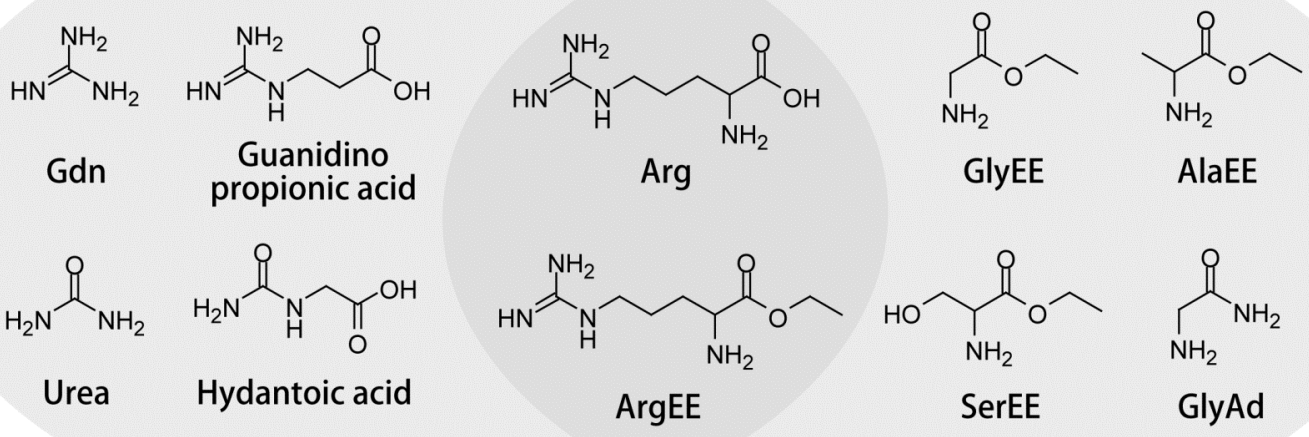

Fig. (6). Typical additives for refolding and heat-induced inactivation of lysozyme. Additives for refolding have the guanidium or ureido group, whereas additives for heat-induced inactivation have an amino acid backbone. Thus, ArgEE is, for example, a favorable additive for both refolding and heating. 


\section{CONCLUSION}

This review summarizes the amine compounds that prevent the heat-induced inactivation of proteins by suppressing chemical modification. We practically recommend the amine co-solute (ex. $50 \mathrm{mM}$ spermidine) in protein solutions when thermal degradation of proteins needs to be avoided. Note that chemical reaction depends on temperature. It is assumed by the Arrhenius equation that heat treatment at $90^{\circ} \mathrm{C}$ for 10 min results in full inactivation $(<10 \%)$ compared with that at $30^{\circ} \mathrm{C}$ for one day. Thus, from the application point of view, it is suggested that amine compounds completely prevent chemical degradation as a preservative additive under the condition of low protein concentration at neutral $\mathrm{pH}$. The simple chemicals that are used as solvent additives will improve protein purification, shipping, storage, and heat treatment for biotechnology and pharmaceutics.

\section{LIST OF ABBREVIATIONS}

$\begin{array}{ll}\text { ArgHCl } & =\text { Arginine monohydrochloride } \\ \text { ArgEE } & =\text { Arginine ethylester } \\ \beta \mathrm{LG} & =\text {-lactoglobulin } \\ \text { FT-IR } & =\text { Glycine amide } \\ \text { GlyAd } & =\text { Glycine ethylester } \\ \text { GlyEE } & =\text { Huanidine } \\ \text { Gdn } & =\text { The time for deamidation of one Asn residue } \\ \tau_{1} & \text { per a protein } \\ \tau_{2} & =\text { Nuclear magnetic resonance } \\ \text { NMR } & =\text { Reduced and carboxymethylated } \\ \text { RCM } & =\text { Ribonuclease A } \\ \text { RNase A } & =\text { The tracthe plasmon resonance } \\ \text { SPR } & \text { TEG }\end{array}$

\section{CONFLICT OF INTEREST}

The author(s) confirm that this article content has no conflict of interest.

\section{ACKNOWLEDGEMENTS}

The authors are grateful for financial support from University of Tsukuba.

\section{REFERENCES}

[1] Manning, M.C.; Chou, D.K.; Murphy, B.M.; Payne, R.W.; Katayama, D.S. Stability of protein pharmaceuticals: An update. Pharm. Res., 2010, 27, 544-575.

[2] Hamada, H.; Arakawa, T.; Shiraki, K. Effect of additives on protein aggregation. Curr. Pharm. Biotechnol., 2009, 10, 400-407.

[3] Shiraki, K.; Kudou, M.; Fujiwara, S.; Imanaka, T.; Takagi, M. Biophysical effect of amino acids on the prevention of protein aggregation. J. Biochem., 2002, 132, 591-595.
Buchner, J.; Rudolph, R. Renaturation, purification and characterization of recombinant Fab-fragments produced in Escherichia coli. Bio/Technol., 1991, 9, 157-162.

Shiraki, K.; Kudou, M.; Nishikori, S.; Kitagawa, H.; Imanaka, T.; Takagi, M. Arginine ethylester prevents thermal inactivation and aggregation of lysozyme. Eur. J. Biochem., 2004, 271, 3242-3247.

Shiraki, K.; Kudou, M.; Sakamoto, R.; Yanagihara, I.; Takagi, M. Amino acid esters prevent thermal inactivation and aggregation of lysozyme. Biotechnol. Prog., 2005, 21, 640-643.

Matsuoka, T.; Tomita, S.; Hamada, H.; Shiraki, K. Amidated amino acids are prominent additives to prevent heat-induced aggregation of lysozyme. J. Biosci. Bioeng., 2007, 103, 440-443.

Hamada, H.; Shiraki, K. L-Argininamide improves the refolding more effectively than L-arginine. J. Biotechnol., 2007, 130, 153160 .

Matsuoka, T.; Hamada, H.; Matsumoto, K.; Shiraki, K. Indispensable structure of solution additives to prevent inactivation of lysozyme for heating and refolding. Biotechnol. Prog., 2009, 25, 1515-1524.

Okanojo, M.; Shiraki, K.; Kudou, M.; Nishikori, S.; Takagi, M. Diamines prevent thermal aggregation and inactivation of lysozyme. J. Biosci. Bioeng., 2005, 100, 556-561.

Kudou, M.; Shiraki, K.; Fujiwara, S.; Imanaka, T.; Takagi, M. Prevention of thermal inactivation and aggregation of lysozyme by polyamines. Eur. J. Biochem., 2003, 270, 4547-4554.

Hirano, A.; Hamada, H.; Shiraki, K. Trans-cyclohexanediamines prevent thermal inactivation of protein: role of hydrophobic and electrostatic interactions. Protein J., 2008, 27, 253-257.

Hirano, A.; Hamada, H.; Okubo, T.; Noguchi, T.; Higashibata, H.; Shiraki, K. Correlation between thermal aggregation and stability of lysozyme with salts described by molar surface tension increment: an exceptional propensity of ammonium salts as aggregation suppressor. Protein J., 2007, 26, 423-433.

Ahern, T.J.; Klibanov, A.M. The mechanisms of irreversible enzyme inactivation at $100^{\circ} \mathrm{C}$. Science, 1985, 228, 1280-1284.

Zale, S.E.; Klibanov, A.M. Why does ribonuclease irreversibly inactivate at high temperatures? Biochemistry, 1986, 25, 54325444.

Volkin, D.B.; Klibanov, A.M. Thermal destruction processes in proteins involving cystine residues. J. Biol. Chem., 1987, 262, 2945-2950.

Volkin, D.B.; Mach, H.; Middaugh, C.R. Degradative covalent reactions important to protein stability. Mol. Biotechnol., 1997, 8, 105-122.

Tyler-Cross, R.; Schirch, V. Effects of amino acid sequence, buffers, and ionic strength on the rate and mechanism of deamidation of asparagine residues in small peptides. J. Biol. Chem., 1991, 266, 22549-22556.

Wright, H.T. Nonenzymatic deamidation of asparaginyl and glutaminyl residues in proteins. Crit. Rev. Biochem. Mol. Biol., 1991, 26, 1-52.

Chelius, D.; Rehder, D.S.; Bondarenko, P.V. Identification and characterization of deamidation sites in the conserved regions of human immunoglobulin gamma antibodies. Anal. Chem., 2005, 77, 6004-6011.

Krokhin, O.V.; Antonovici, M.; Ens, W.; Wilkins, J.A.; Standing, K.G. Deamidation of -Asn-Gly- sequences during sample preparation for proteomics: Consequences for MALDI and HPLC-MALDI analysis. Anal. Chem., 2006, 78, 6645-6650.

Patel, K.; Borchardt, R.T. Chemical pathways of peptide degradation. II. Kinetics of deamidation of an asparaginyl residue in a model hexapeptide. Pharm. Res., 1990, 7, 703-711.

Cohen, S.L.; Price, C.; Vlasak, J. $\beta$-elimination and peptide bond hydrolysis: Two distinct mechanisms of human IgG1 hinge fragmentation upon storage. J. Am. Chem. Soc., 2007, 129, 6976-6977. Wang, Z.; Rejtar, T.; Zhou, Z.S.; Karger, B.L. Desulfurization of cysteine-containing peptides resulting from sample preparation for protein characterization by mass spectrometry. Rapid Commun. Mass Spectrom., 2010, 24, 267-275.

Ahern, T.J.; Klibanov, A.M. Analysis of processes causing thermal inactivation of enzymes. Methods Biochem. Anal., 1988, 33, 91127.

Florence, T.M. Degradation of protein disulphide bonds in dilute alkali. Biochem. J., 1980, 189, 507-520.

Wang, W. Protein aggregation and its inhibition in biopharmaceutics. Int. J. Pharm., 2005, 289, 1-30. 
[28] Davies, M.J. The oxidative environment and protein damage. Biochim. Biophys. Acta, 2005, 1703, 93-109.

[29] Takai, E.; Kitamura, T.; Kuwabara, J.; Ikawa, S.; Yoshizawa, S.; Shiraki, K.; Kawasaki, H.; Arakawa, R.; Kitano, K. Chemical modification of amino acids by atmospheric-pressure cold plasma in aqueous solution. J. Phys. D: Appl. Phys., 2014, 47, 285403.

[30] Joshi, A.B.; Sawai, M.; Kearney, W.R.; Kirsch, L.E. Studies on the mechanism of aspartic acid cleavage and glutamine deamidation in the acidic degradation of glucagon. J. Pharm. Sci., 2005, 94, 19121927.

[31] Tomita, S.; Shiraki, K. Why do solution additives suppress the heat-induced inactivation of proteins? inhibition of chemical modifications. Biotechnol. Prog., 2011, 27, 855-862.

[32] Kurinomaru, T.; Kameda, T.; Shiraki, K. Effects of hydrophobicity and multivalency of polyamines on enzyme hyperactivation of $\alpha$ chymotrypsin. J. Mol. Catal. B: Enzymatic, 2015, 115, 135-139.

[33] Arakawa, T.; Kita, Y. Multi-faceted arginine: mechanism of the effects of arginine on protein. Curr. Protein Pept. Sci., 2014, 15, 608-620.

[34] Rudolph, R.; Lilie, H. In vitro folding of inclusion body proteins. FASEB J., 1996, 10, 49-56.

[35] Lilie, H.; Schwarz, E.; Rudolph, R. Advances in refolding of proteins produced in E. coli. Curr. Opin. Biotechnol., 1998, 9, 497501.

[36] Lange, C.; Rudolph, R. Suppression of protein aggregation by Larginine. Curr. Pharm. Biotechnol., 2009, 10, 408-414.

[37] Buchner, J.; Pastan, I.; Brinkmann, U. A method for increasing the yield of properly folded recombinant fusion proteins: Single-chain immunotoxins from renaturation of bacterial inclusion bodies. Anal. Biochem., 1992, 205, 263-270.

[38] Kohnert, U.; Rudolph, R.; Verheijen, J.H.; Weening-Verhoeff, E.J.; Stern, A.; Opitz, U.; Martin, U.; Lill, H.; Prinz, H.; Lechner, M.; Kresse, G.B.; Bucket, P.; Fischer, S. Biochemical properties of the kringle 2 and protease domains are maintained in the refolded t-PA deletion variant BM 06.022. Protein Eng., 1992, 5, 93-100.

[39] Lin, W.J.; Traugh, J.A. Renaturation of casein kinase II from recombinant subunits produced in Escherichia coli: Purification and characterization of the reconstituted holoenzyme. Protein Expr. Purif., 1993, 4, 256-264.

[40] Stoyan, T.; Michaelis, U.; Schooltink, H.; Van Dam, M.; Rudolph, R.; Heinrich, P.C.; Rose-John, S. Recombinant soluble human interleukin-6 receptor. Expression in Escherichia coli, renaturation and purification. Eur. J. Biochem., 1993, 216, 239-245.

[41] Ahn, J.H.; Lee, Y.P.; Rhee, J.S. Investigation of refolding condition for Pseudomonas fluorescens lipase by response surface methodology. J. Biotechnol., 1997, 54, 151-160.

[42] Suenaga, M.; Ohmae, H.; Tsuji, S.; Itoh, T.; Nishimura, O. Renaturation of recombinant human neurotrophin-3 from inclusion bodies using a suppressor agent of aggregation. Biotechnol. Appl. Biochem., 1998, 28, 119-124.

[43] Tsumoto, K.; Shinoki, K.; Kondo, H.; Uchikawa, M.; Juji, T.; Kumagai, I. Highly efficient recovery of functional single-chain Fv fragments from inclusion bodies overexpressed in Escherichia coli by controlled introduction of oxidizing reagent-application to a human single-chain Fv fragment. J. Immunol. Methods, 1998, 219, 119-129.

[44] Asano, R.; Kudo, T.; Makabe, K.; Tsumoto, K.; Kumagai, I. Antitumor activity of interleukin-21 prepared by novel refolding procedure from inclusion bodies expressed in Escherichia coli. FEBS Lett., 2002, 528, 70-76.

[45] Fujiwara, Y.; Aiki, Y.; Yang, L.; Takaiwa, F.; Kosaka, A.; Tsuji, N.M.; Shiraki, K.; Sekikawa, K. Extraction and purification of human interleukin-10 from transgenic rice seeds. Protein Expr. Purif., 2010, 72, 125-130.

[46] Umetsu, M.; Tsumoto. K.; Hara, M.; Ashish, K.; Goda, S.; Kumagai, I. How additives influence the refolding of immunoglobulinfolded proteins in a stepwise dialysis system. Spectroscopic evidence for highly efficient refolding of a single-chain Fv fragment. J. Biol. Chem. 2003, 278, 8979-8987.

[47] Fujimoto, A.; Hirano, A.; Shiraki, K. Ternary system of solution additives with arginine and salt for refolding of $\beta$-galactosidase. Protein J., 2010, 29, 161-166.

[48] Kudou, M.; Ejima, D.; Sato, H.; Yumioka, R.; Arakawa, T.; Tsumoto, K Refolding single-chain antibody (scFv) using lauroyl-Lglutamate as a solubilization detergent and arginine as a refolding additive. Protein Expr. Purif. 2011, 77, 68-74.
[49] Gunda, V.; Boosani, C.S.; Verma, R.K.; Guda, C.; Sudhakar, Y.A. L-Arginine mediated renaturation enhances yield of human, $\alpha 6$ Type IV collagen non-collagenous domain from bacterial inclusion bodies. Protein Pept. Lett. 2012, 19, 1112-1121.

[50] Flocco, M.M.; Mowbray, S.L. Planar stacking interactions of arginine and aromatic side-chains in proteins. J. Mol. Biol., 1994, 235, 709-717.

[51] Mitchell, J.B.; Nandi, C.L.; McDonald, I.K.; Thornton, J.M.; Price, S.L. Amino/aromatic interactions in proteins: is the evidence stacked against hydrogen bonding? J. Mol. Biol. 1994, 239, 315331.

[52] Schug, K.A.; Lindner, W. Noncovalent binding between guanidinium and anionic groups: Focus on biological- and synthetic-based arginine/guanidinium interactions with phosph[on]ate and sulf[on]ate residues. Chem. Rev., 2005, 105, 67-114.

[53] Shah, D.; Li, J.; Shaikh, A.R.; Rajagopalan, R. Arginine-aromatic interactions and their effects on arginine-induced solubilization of aromatic solutes and suppression of protein aggregation. Biotechnol. Prog. 2012, 28, 223-231.

[54] Arakawa, T.; Kitam Y.; Koyama. A.H. Solubility enhancement of gluten and organic compounds by arginine. Int. J. Pharm., 2008, 355, 220-223.

[55] Takai, E.; Yoshizawa, S.; Ejima, D.; Arakawa, T.; Shiraki, K. Synergistic solubilization of porcine myosin in physiological salt solution by arginine. Int. J. Biol. Macromol., 2013, 62, 647-651.

[56] Arakawa, T.; Tsumoto, K. The effects of arginine on refolding of aggregated proteins: not facilitate refolding, but suppress aggregation. Biochem. Biophys. Res. Commun., 2003, 304, 148-152.

[57] Ishibashi, M.; Tsumoto, K.; Tokunaga, M.; Ejima, D.; Kita, Y.; Arakawa, T. Is arginine a protein-denaturant? Protein Expr. Purif., 2005, 42, 1-6.

[58] Ito, L.; Shiraki, K.; Matsuura, T.; Okumura, M.; Hasegawa, K. Baba, S.; Yamaguchi, H.; Kumasaka, T. High-resolution X-ray analysis reveals binding of arginine to aromatic residues of lysozyme surface: Implication of suppression of protein aggregation by arginine. Protein Eng., 2011, 24, 269-274.

[59] Nakakido, M.; Tanaka, Y.; Mitsuhori, M.; Kudou, M.; Ejima, D.; Arakawa, T.; Tsumoto, K. Structure-based analysis reveals hydration changes induced by arginine hydrochloride. Biophys. Chem., 2008, 137, 105-109.

[60] Hirano, A.; Arakawa, T.; Shiraki, K. Arginine increases the solubility of coumarin: Comparison with salting-in and salting-out additives. J. Biochem., 2008, 144, 363-369.

[61] Hirano, A.; Kameda, T.; Arakawa, T.; Shiraki, K. Arginine-assisted solubilization system for drug substances: Solubility experiment and simulation. J. Phys. Chem. B, 2010, 114, 13455-13462.

[62] Arakawa, T.; Hirano, A.; Shiraki, K.; Kita, Y.; Koyama, A.H. Stabilizing and destabilizing effects of arginine on deoxyribonucleic acid. Int. J. Biol. Macromol., 2010, 46, 217-222.

[63] Hirano, A.; Tokunaga, H.; Tokunaga, M.; Arakawa, T.; Shiraki, K. The solubility of nucleobases in aqueous arginine solutions. Arch. Biochem. Biophys., 2010, 497, 90-96.

[64] Ariki, R.; Hirano, A.; Arakawa, T.; Shiraki, K. Arginine increases the solubility of alkyl gallates through interaction with the aromatic ring. J. Biochem., 2011, 149, 389-394.

[65] Hirano, A.; Kameda, T.; Shinozaki, D.; Arakawa, T.; Shiraki, K. Molecular dynamics simulation of the arginine-assisted solubilization of caffeic acid: Intervention in the interaction. J. Phys. Chem. $B$, 2013, 117, 7518-7527.

[66] Baynes, B.M.; Trout, B.L. Rational design of solution additives for the prevention of protein aggregation. Biophys. J., 2004, 87, 16311639.

[67] Baynes, B.M.; Wang, D.I.; Trout, B.L. Role of arginine in the stabilization of proteins against aggregation. Biochemistry, 2005, 44, 4919-4925.

[68] Shukla, D.; Trout, B.L. Interaction of arginine with proteins and the mechanism by which it inhibits aggregation. J. Phys. Chem. B, 2010, 114, 13426-13438.

[69] Vagenende, V.; Han, A.X.; Mueller, M.; Trout, B.L. Proteinassociated cation clusters in aqueous arginine solutions and their effects on protein stability and size. ACS Chem. Biol., 2013, 8, 416422.

[70] Woods, A.S. The mighty arginine, the stable quaternary amines, the powerful aromatics, and the aggressive phosphate: Their role in the noncovalent minuet. J. Proteome Res., 2004, 3, 478-484. 
[71] Crowley, P.B.; Golovin, A. Cation- $\pi$ interactions in protein-protein interfaces. Proteins, 2004, 59, 231-239.

[72] Luo, R.; David, L.; Hung, H.; Devaney, J.; Gilson, M.K. Strength of Solvent-Exposed Salt-Bridges. J. Phys. Chem. B, 1999, 103, 727-736.

[73] Springs, B.; Haake, P. Equilibrium constants for association of guanidinium and ammonium ions with oxyanions: The effect of changing basicity of the oxyanion. Bioorg. Chem., 1977, 6, 181190 .

[74] Shah, D.; Shaikh, A.R.; Peng, X.; Rajagopalan, R. Effects of arginine on heat-induced aggregation of concentrated protein solutions. Biotechnol. Prog., 2011, 27, 513-520.

[75] Arakawa, T.; Timasheff, S.N. Preferential interactions of proteins with solvent components in aqueous amino acid solutions. Arch. Biochem. Biophys., 1983, 224, 169-177.

[76] Arakawa, T.; Timasheff, S.N. Preferential interactions of proteins with salts in concentrated solutions. Biochemistry, 1982, 21, 65456552.

[77] Arakawa, T.; Timasheff, S.N. Mechanism of protein salting in and salting out by divalent cation salts: Balance between hydration and salt binding. Biochemistry, 1984, 23, 5912-5923.

[78] Arakawa, T.; Ejima, D.; Tsumoto, K.; Obeyama, N.; Tanaka, Y.; Kita, Y.; Timasheff, S.N. Suppression of protein interactions by arginine: a proposed mechanism of the arginine effects. Biophys. Chem., 2007, 127, 1-8.

[79] Inoue, N.; Takai, E.; Arakawa, T.; Shiraki, K. Arginine and lysine reduce the high viscosity of serum albumin solutions for pharmaceutical injection. J. Biosci. Bioeng., 2014, 117, 539-543.

[80] Inoue, N.; Takai, E.; Arakawa, T.; Shiraki, K Specific decrease in solution viscosity of antibodies by arginine for therapeutic formulations. Mol. Pharm., 2014, 11, 1889-1896.

[81] Cirkovas, A.; Sereikaite, J. Different effects of L-arginine on the heat-induced unfolding and aggregation of proteins. Biologicals, 2011, 39, 181-188.

[82] Fukuda, M.; Kameoka, D.; Torizawa, T.; Saitoh, S.; Yasutake, M.; Imaeda, Y.; Koga, A.; Mizutani, A. Thermodynamic and fluorescence analyses to determine mechanisms of IgG1 stabilization and destabilization by arginine. Pharm. Res., 2014, 31, 992-1002.

[83] Takai, E.; Uda, K.; Matsushita, S.; Shikiya, Y.; Yamada, Y.; Shiraki, K.; Zako, T.; Maeda, M. Cysteine inhibits amyloid fibrillation of lysozyme and directs the formation of small worm-like aggregates through non-covalent interactions. Biotechnol. Prog., 2014, 30, 470-478.

[84] Clark, E.D. Refolding of recombinant proteins. Curr. Opin. Biotechnol., 1998, 9, 157-163.

[85] Clark, E.D. Protein refolding for industrial processes. Curr. Opin. Biotechnol., 2001, 12, 202-207.

[86] Maeda, Y.; Koga, H.; Yamada, H.; Ueda, T.; Imoto, T. Effective renaturation of reduced lysozyme by gentle removal of urea. Protein Eng., 1995, 8, 201-205.

[87] Rozema, D.; Gellman, S.H. Artificial chaperone-assisted refolding of denatured-reduced lysozyme: Modulation of the competition between renaturation and aggregation. Biochemistry, 1996, 35, 15760-15771.

[88] Wang, S.; Raghani, A. Arginine as an eluent for automated on-line Protein $\mathrm{A} /$ size exclusion chromatographic analysis of monoclonal antibody aggregates in cell culture. J. Chromatogr. B, 2014, 945 , 115-120.

[89] Tsumoto, K.; Umetsu, M.; Kumagai, I.; Ejima, D.; Arakawa, T. Solubilization of active green fluorescent protein from insoluble particles by guanidine and arginine. Biochem. Biophys. Res. Commun., 2003, 312, 1383-1386.

[90] Hamada, H.; Takahashi, R.; Noguchi, T.; Shiraki, K. The differences in the effect of solution additives on heat- and refoldinginduced aggregation. Biotechnol. Prog., 2008, 24, 436-443.

[91] Tomita, S.; Tanabe, Y.; Shiraki, K. Oligoethylene glycols prevent thermal aggregation of $\alpha$-chymotrypsin in a temperature-dependent manner: implications for design guidelines. Biotechnol. Prog., 2013, 29, 1325-1330.

[92] Raina, A.; Jänne, J. Physiology of the natural polyamines putrescine, spermidine and spermine. Med. Biol., 1975, 53, 121-147.

[93] Robert, A.; Casero, Jr.; Anthony, E. Polyamine catabolism and disease. Biochem. J., 2009, 421, 323-338.

[94] Minois, N.; Carmona-Gutierrez, D.; Madeo, F. Polyamines in aging and disease. Aging, 2011, 3, 716-732.

[95] Yancey, P.H.; Clark, M.E.; Hand, S.C.; Bowlus, R.D.; Somero, G.N. Living with water stress: evolution of osmolyte systems. Science, 1982, 217, 1214-1222.

[96] Perl, D.; Welker, C.; Schindler, T.; Schröder, K.; Marahiel, MA Jaenicke, R.; Schmid, F.X. Conservation of rapid two-state folding in mesophilic, thermophilic and hyperthermophilic cold shock proteins. Nat. Struct. Biol., 1998, 5, 229-35.

[97] Motono, C.; Yamagishi, A.; Oshima, T. Urea-induced unfolding and conformational stability of 3-isopropylmalate dehydrogenase from the thermophile thermus thermophilus and its mesophilic counterpart from Escherichia coli. Biochemistry, 1999, 38, 13321337.

[98] Shiraki, K.; Nishikori, S.; Fujiwara, S.; Hashimoto, H.; Kai, Y Takagi, M.; Imanaka, T. Comparative analyses of the conformational stability of a hyperthermophilic protein and its mesophilic counterpart. Eur. J. Biochem., 2001, 268, 4144-4150.

[99] Vieille, C.; Zeikus, G.J. Hyperthermophilic enzymes: sources, uses, and molecular mechanisms for thermostability. Microbiol. Mol. Biol. Rev., 2001, 65, 1-43.

[100] Kumar, S.; Tsai, C.J.; Nussinov, R. Factors enhancing protein thermostability. Protein Eng., 2000, 13, 179-191.

[101] Zhou, X.X.; Wang, Y.B.; Pan, Y.J.; Li, W.F. Differences in amino acids composition and coupling patterns between mesophilic and thermophilic proteins. Amino Acids, 2008, 34, 25-33.

[102] Chelius, D.; Rehder, D.S.; Bondarenko, P.V. Identification and characterization of deamidation sites in the conserved regions of human immunoglobulin gamma antibodies. Anal. Chem., 2005, 77, 6004-6011.

[103] Oshima, T. Unique polyamines produced by an extreme thermophile, Thermus thermophilus. Amino Acids, 2007, 33, 367-372.

[104] Oshima, T. Thermine: a new polyamine from an extreme thermophile. Biochem. Biophys. Res. Commun., 1975, 63, 1093-1098.

[105] Oshima, T. A new polyamine, thermospermine, 1,12-diamino-4,8diazadodecane, from an extreme thermophile. J. Biol. Chem., 1979 $254,8720-8722$
Received: April 28, 2015

Revised: August 31, 2015

Accepted: September 22, 2015 